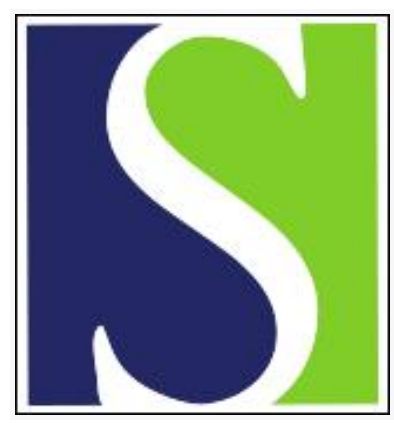

Scand J Work Environ Health 2014;40(1):96-99

https://doi.org/10.5271/sjweh.3396

Published online: 28 Oct 2013, Issue date: 01 Jan 2014

Randomized controlled trials are needed to close the evidence gap in the prevention of preterm birth

by Kwegyir-Afful E, ljaz S, Räsänen K, Verbeek J

Pregnant women have been advised to avoid heavy lifting during pregnancy due to concerns of adverse pregnancy outcomes including premature delivery. To date there is no evidence on the effectiveness of advice in preventing preterm birth as found in a recent systematic search and appraisal of published literature. This letter employs the findings of the review to inform future studies.

Affiliation: Finnish Institute of Occupational Health, PO Box 310, 70701 Kuopio, Finland. emmakwe@student.uef.fi

Refers to the following texts of the Journal: 2013;39(4):325-334 2013;39(1):88-95

Key terms: evidence gap; health education; heavy lifting; infant morbidity; physical activity; pregnancy; pregnant working women; premature birth; premature delivery; prematurity; preterm birth; prevention; randomized controlled trial

This article in PubMed: www.ncbi.nlm.nih.gov/pubmed/24165888 


\title{
Randomized controlled trials are needed to close the evidence gap in the prevention of preterm birth
}

\author{
by Emma Kwegyir-Afful, MPH, ${ }^{1,2}$ Sharea ljaz, MPH, ${ }^{1}$ Kimmo Räsänen, MD, PhD, ${ }^{1,2}$ Jos Verbeek, MD, PhD ${ }^{1}$
}

Kwegyir-Afful E, ljaz S, Räsänen K, Verbeek J. Randomized controlled trials are needed to close the evidence gap in the prevention of preterm birth. Scand J Work Environ Health. 2014;40(1):96-99. doi:10.5271/sjweh.3396

Prematurity ( $<37$ weeks gestation) is among the major determinants of infant morbidity and mortality (1). Within developing countries, where the condition is of major public health importance, incidence is around $19 \%$ versus $5-7 \%$ in developed nations (2). The global estimation of preterm delivery in 2005 was $9.6 \%$ of all births, which is a total of 12.9 million, 11 million of which were from Africa and Asia. About 28\% of infant deaths occurring within the first seven days of life are a result of prematurity (3). Apart from the negative health implications of prematurity, the monetary cost is very alarming, with America alone spending over \$26.2 billion on medical and educational interventions in addition to the cost of productivity loss (3). Despite global and local achievements in the survival rate of premature infants, the rate of prematurity keeps rising (4).

The role of women in society has changed dramatically as today's woman has a higher chance of going to school and getting employed outside the home than her mother (5). There is plausibility of heavy lifting ( $>5$ days per week) in the causal pathway of premature delivery (6). Long working hours and heavy lifting are alleged to be associated with preterm delivery (7). Whilst some studies conclude there is a causal link between heavy lifting and preterm birth, another study concluded that, regardless of the exposure periods and the frequency of lifting, there is no significant association between heavy lifting and preterm birth (8). In a recent National Birth Cohort in Denmark, researchers published in the Scandinavian Journal of Work, Environment and Health concluded that occupational lifting of medium-to-heavy loads can lead to pelvic pain during pregnancy (9) whilst pelvic pain is a common signal of labor initiation.

Interventions, such as health education, mater- nity leave, or reassignment to a less-physical task, are already in place in most Western countries to prevent exposure to heavy lifting at work among pregnant women. However, it is unclear which intervention produces better pregnancy outcomes. A systematic review (10) on the effects of bed rest as a preventive measure of preterm birth compared to no intervention among high-risk singleton pregnant women found no evidence to support this preventive measure. No other reviews on the comparative effectiveness of preventive measures for heavy lifting in preventing preterm birth were found.

We therefore performed a systematic review of the published literature to locate evaluation studies of interventions to prevent heavy lifting during pregnancy. We searched for randomized or quasi-randomized controlled trials (RCT/quasi RCT) comprising pregnant employees exposed to lifting tasks, which evaluated an intervention aimed at decreasing lifting exposure and the effects on the incidence of prematurity. Based on these inclusion criteria we developed a search strategy and searched the databases Medline (via PubMed), Scopus, and CINAHL up to 28 June 2012 (see appendix for full search strategy). Two authors independently scrutinized the references for eligible trials but none fulfilled our inclusion criteria. A further search of reference lists of potentially relevant studies also failed to identify any RCT.

Thus, the hypothesis that an intervention that decreases heavy lifting exposure among pregnant woman may have a positive impact on pregnancy outcomes could be not proven either right or wrong. We went strictly for RCT because of the quality in terms of study design (11) as rigorous procedures are carried out to establish the cause and effect relationship between an outcome and intervention (12). Nevertheless, our search

1 Finnish Institute of Occupational Health, PO Box 310, 70701 Kuopio, Finland.

2 University of Eastern Finland, School of Medicine, Institute of Public Health and Clinical Nutrition, Kuopio, Finland.

3 Correspondence to: Emma Kwegyir-Afful, MPH, Finnish Institute of Occupational Health, PO Box 310, 70701 Kuopio, Finland. [E-mail: emmakwe@student.uef.fi] 
did yield five observational studies that did not fit the inclusion criteria (RCT, pregnant employees as subjects, exposure to heavy-lifting tasks, and an intervention aiming at decreasing lifting exposure). Three of the studies investigated a causal association between preterm birth and heavy lifting whilst two were intervention studies. The three exposure studies $(6,13,14)$ indicated a negative impact of occupational exposure to strenuous physical activities on gestational age. One literature review suggested that exercise could be beneficial and an observational evaluation study concluded that current legislation in Germany sufficiently protects pregnant women against preterm birth $(15,16)$. However, their lack of validity and greater margins of errors associated with the studies' designs make it difficult to rely on these observational studies.

Existing systematic reviews of exposure are inconclusive on the subject matter. A meta-analysis indicated a statistically significant association between preterm birth and physically demanding work (5). Similarly, a systematic review (17) suggested a possible association between lifting and prematurity. In contradiction to these results, a third systematic review (18) refuted an association between lifting, especially during the first trimester, and premature delivery. This review was recently updated and came to similar conclusions (19). In spite of this, another Scand J Work Environ Health systematic review of the risk of miscarriage due to exposure to lifting during pregnancy cautions against lifting high loads during pregnancy (20).

A phenomenon that characterized the identified primary studies was misclassification of exposure. The flaws in the estimation of especially the exposure severely hamper the drawing of strong conclusions in these studies and reviews. In almost all the studies, women self-reported their lifting exposure retrospectively or prospectively. It is unsure if the subjective measurement of exposure leads to non-differential misclassification. It has been argued that differential misclassification usually leads to an underestimation of the relation between exposure and outcome if there is any, but this is surrounded by uncertainty especially when exposure is on a continuous scale (21). It could be that misclassification is differential in case-control studies. Among cases, lifting exposure could be better remembered and reported as a result of recall bias. Therefore, there is a need for a high quality evaluation study in which a group of pregnant women with heavy lifting exposure are subjected to an intervention that decreases the exposure while a second group of unexposed women serves as a control. Such a study would provide reliable evidence for both an effect of the intervention and a causal relation (22).

There are several possible explanations for the absence of high quality studies to support practice. To start, financial support is a major factor in every research. A substantial amount of money is required to conduct a high quality study. In low- and middleincome countries, where strenuous physical activity and premature birth are common occurrences $(3,6)$, access to finance to conduct research is always a challenge as evidenced by the "10/90 gap", which indicates only $10 \%$ of global resources are earmarked for health research addressing $90 \%$ of global disease burden (23). Secondly, ethical considerations can also be a limiting factor. Human lives are involved and there may be ethical issues as to who should and should not be advised to avoid heavy lifting given the current uncertainty about the evidence necessitating precautionary measures (5). Thirdly, an RCT requires recruitment of participants from the first trimester to determine the consequences of varied exposure to strenuous work during the three different trimesters, however, the chances of attrition can be high due to the length of the study. Finally, in high income countries where health research is more common, there already exists legislation on maternity leave that protects pregnant women and therefore researchers may not have enough motivation to carry out such studies.

Education to decrease physical activity during pregnancy has been shown to be effective for improving patients' outcome and the prevention of unwanted occurrences such as prematurity (24). However, there is currently no evidence to support or refute its implementation for women who are exposed to lifting during pregnancy. Due to the aforementioned inconclusive nature and the methodological flaws in available studies, an RCT is needed to fill the gap.

Such an ideal future RCT would hypothesize a reduction in the incidence of preterm birth among pregnant women who receive an intervention to avoid heavy lifting. The intervention could consist of health education pointing out the possibilities to avoid heavy lifting during pregnancy. The study should be a prospective two-arm RCT that is parallel and pragmatic to ascertain the effectiveness of the intervention. Looking at the global trends of premature birth, the appropriate trial must be centered within Asia or Africa because these continents have the highest proportions of preterm birth of $54 \%$ and $31 \%$, respectively, in the world (3). Recruitment of participants could be done with the assistance of staff of antenatal clinics. Eligibility criteria for participants could be: women whose pregnancy has not gone beyond 12 weeks, singleton pregnancy, and women who are exposed to heavy lifting $(\geq 10 \mathrm{~kg}$ ) either at home or at work $\geq 10$ times per day.

Eligible participants would be assigned to either the experimental or control group at different antenatal clinics using an appropriate randomization method. Proper randomization will generate two groups that are equal in known and unknown extraneous variables with the 
exception of the intervention. To prevent contamination of the control group with the treatment of the intervention group when they are both attending the same clinic, randomization of antenatal clinics with their patients to either the intervention or the control group in a cluster randomized design would be desirable. Again, it will be difficult to realize randomization at the individual level in developing countries as a result of high cost and the complex nature of data collection (25).

A sufficiently varied intensity of the health education intervention should be given to the treatment group during antenatal sessions with the content focusing on the meaning of heavy lifting, the possible implications of heavy lifting during pregnancy, encouragement of avoidance of lifting, and means to avoid lifting. The intervention could be elaborated further to ensure that this advice can also be implemented into practice. On the other hand, the control group should receive routine health education during their antenatal sessions. It would be important to monitor the level of exposure to heavy lifting in both groups to be able to show that the intervention had indeed been effective in the intervention group.

For the outcome, the future study should measure the length of pregnancy according to the four subgroups of gestational age described by Goldenberg et al (26): births that occur at $<28,28-31,32-33$, and $34-36$ weeks of gestation. Measurement of the gestational age should preferably be based on methods such as calculation of the expected date of delivery using the woman's last menstrual period, abdominal examination, and ultrasonography, which are also feasible in developing countries. The effect of the intervention could then be measured as the mean difference in the length of pregnancy in days among mothers in the intervention compared to control group. The resultant mean difference of gestational age between the two arms would then determine the advantageous effects or otherwise of the intervention for the intervention versus control group. The effect should be adjusted for the clustering effect of the antenatal clinics. When the exposure to lifting is measured appropriately, it can be measured if the intervention effect varies with the level of exposure.

The sample size of the trial should be large enough to be able to find a relevant difference of two weeks between the comparable groups.

Getting stronger evidence to inform practice and policy direction is essential. Reassigning an employee or providing a paid maternity leave can negatively affect productivity therefore employers must be convinced as to why they need to grant their pregnant employees these benefits and the pregnant worker must understand why she needs to avoid heavy lifting.

\section{References}

1. World Health Organization (WHO) Media Centre Fact Sheet No. 363. Preterm Birth. Paris: WHO; November 2012. http:// www.who.int/mediacentre/factsheets/fs363/en/index.html]

2. Valero de Bernabe J, Soriano T, Albaladejo R, Juarranz M, Calle ME, Martinez D, Dominquez-Rojas V. Risk factors for low birth weight: a review. Eur J Obstet Gynecol Reprod Biol. 2004;116(1):3-15. http://dx.doi.org/10.1016/j. ejogrb.2004.03.007.

3. Beck S, Wojdyla D, Say L, Betran AP, Merialdi M, Requejo JH, Rubens C, Menon R, Van Look PF. The worldwide incidence of preterm birth: a systematic review of maternal mortality and morbidity. Bulletin of the World Health Organization. 2010;88(1):31-38. http://dx.doi.org/10.2471/ BLT.08.062554.

4. EXPRESS Group, Fellman V, Hellsström-Westas L, Norman M, Westgren M, Källen K, Lagercranttz $\mathrm{H}$ et al. One-year survival of extremely preterm infants after active perinatal care in Sweden. JAMA. 2009;301(21):2225-33. http://dx.doi. org/10.1001/jama.2009.771.

5. Mozurkewich EL, Luke B, Avni M, Wolf F.M. Working conditions and adverse pregnancy outcomes. A meta-analysis ACOG. 2000;95(4):623-35.

6. Agbla FA, Ergin A, Boris NW. Occupational working conditions as risk factors for preterm birth in Benin. Rev Epidemiol Sante Publique. 2006;54(2):157-65. http://dx.doi. org/10.1016/S0398-7620(06)76709-8.

7. Croteau R, Marcoux S, Brisson C. Work activity in pregnancy, preventive measures, and the risk of preterm delivery. Am J Epidemiol. 2007;166(8):951-65. http://dx.doi.org/10.1093/ aje/kwm171

8. Pompeii LA, Evenson KR, Rogers B, McMahon M, Savitz DA. Physical exertion at work and the risk of preterm delivery and small-for-gestational-age birth. Obstet Gynecol. 2005;106(6):1279-88. http://dx.doi.org/10.1097/01. AOG.0000189080.76998.f8.

9. Larsen PS, Strandberg-Larsen K, Juhl M, Svendsen SW, Bonde JP, Anderson AM. Occupational lifting and pelvic pain during pregnancy: a study within the Danish National Birth Cohort. Scand J Work Environ Health. 2013;39(1):88-95. http:// dx.doi.org/10.5271/sjweh.3304.

10. Sosa C, Althabe F, Belizan JM, Bergel E. Bedrest in singleton pregnancies for preventing preterm birth (Cochrane Review). The Cochrane Library; 2010;(1). (Art No.: CD003581. CD003581.pub2.) http://dx.doi.org/10.1002/14651858.

11. Evans D. Hierarchy of evidence: a framework for ranking evidence evaluating healthcare interventions. J Clin Nursing. 2002;12(1):77-84. http://dx.doi.org/10.1046/j.13652702.2003.00662.x.

12. Kendall JM. Designing a research project: randomized controlled trials and their principles. Emerg Med J. 2003;20(2):164-8. http://dx.doi.org/10.1136/emj.20.2.164.

13. Simpson JL. Are physical activity and employment related 
to preterm birth and low birth weight? Am J Obstet Gynecol. 1993;168(4):1231-8. http://dx.doi.org/10.1016/00029378(93)90374-R.

14. Biernacka JB, Hanke W, Makowiec-Dabrowska T, Makowska Z, Sobala W. Occupation-related psychosocial factors in pregnancy and risk of preterm delivery. Med Pr. 2007;58(3):205-15.

15. Henrich W, Schmider A, Fuchs I, Schmidt F, Dudenhausen JW. The effects of working conditions and antenatal leave for the risk of premature birth in Berlin. Arch Gynecol Obstet. 2003;269:379. http://dx.doi.org/10.1007/s00404-003-0487-8.

16. Domingues MR, Matijasevich A, Barros AJ. Physical Activity and Preterm Birth- A Literature Review. Sports Medicine. 2009;39(11):961-75. http://dx.doi.org/10.2165/11317900000000000-00000.

17. NHS Plus, Royal College of Physicians, Faculty of Occupational Medicine. Physical and shift work in pregnancy: occupational aspects of management. A national guideline. London: RCP, 2009.

18. Bonzini M, Coggon D, Palmer KT. Risk of prematurity, low birth weight and pre-eclampsia in relation to working hours and physical activities: a systematic review. Occup Environ Med. 2007; 64:228-43. http://dx.doi.org/10.1136/ oem.2006.026872.

19. Palmer KT, Bonzini M, Harris EC, Linaker C, Bonde JP. Work activities and risk of prematurity, low birth weight and pre-eclampsia: an updated review with meta-analysis. Occup Environ Med. 2013;70(4):213-22. http://dx.doi.org/10.1136/ oemed-2012-101032.

20. Bonde JP, Jørgensen KT, Bonzini M, Palmer KT. Miscarriage and occupational activity: a systematic review and metaanalysis regarding shift work, working hours, lifting, standing, and physical workload. Scand J Work Environ Health. 2013;39(4):325-34. http://dx.doi.org/10.5271/sjweh.3337.
21. Rothman KJ, Greenland, S. and Lash, TL. Validity in Epidemiologic studies. In: Rothman KJ, Greenland S, Lash LT. (eds.) Modern epidemiology. Third ed. Philadelphia, USA: Lippincott Williams and Wilkins; 2008. p128.

22. Kristensen TS. Intervention studies in occupational epidemiology. Occup Environ Med. 2005; 62(3):205-10. http://dx.doi.org/10.1136/oem.2004.016097.

23. Frenk J. Health needs and the global research agenda. World Health Organization: 2004 Nov; MacroHealth Newsletter Issue No 11, p1.

24. Overgaard PM. Patient teaching in five easy steps. Nursing made Incredibly Easy. May/June 2009; 7(3):56. http:// dx.doi.org/10.1097/01.NME.0000350942.73025.3f.

25. Donner A. The role of cluster randomization trials in health research (power point presentation). (Internet). University of Western Ontario London, Canada; Department of Epidemiology and Biostatistics; 2011 (cited 2013 Apr 18). Available from: http://www.newton.ac.uk/programmes/ DAE/seminars/2011081514001.pdf.

26. Goldenberg RL, Culhane JF, Iams JD, Romero R. Epidemiology and causes of preterm birth. Lancet. 2008;371(9606):75-84. http://dx.doi.org/10.1016/S01406736(08)60074-4.

27. Mamelle N, Laumon B, Lazar P. Prematurity and occupational activity during pregnancy. Am J Epidemiol. 1984;119(3):309-22.

28. Evidence-Based Practice in the Health Sciences; EvidenceBased Nursing. Levels of evidence (Internet). Chicago: Information Services Department of the Library of the Health Sciences (updated 2006 Sept 26; cited 2012 May 4). Available from: http://ebp.lib.uic.edu/nursing/node/12/.

Received for publication: 16 July 2013

\begin{tabular}{|l|l|l|l|l|}
\hline \multicolumn{2}{|l|}{ Appendix. PubMed search strategy } \\
\hline Search & $\begin{array}{l}\text { Add to } \\
\text { builder }\end{array}$ & Query & $\begin{array}{l}\text { Items } \\
\text { found }\end{array}$ & Time \\
\hline & & & & \\
\hline$\# 17$ & Add & $\begin{array}{l}\text { Search ("Motor Activity"(Mesh) AND \#13 AND prematur* Filters: } \\
\text { Humans; Randomized Controlled Trial }\end{array}$ & $\underline{3}$ & $01: 55: 50$ \\
\hline$\# 16$ & $\underline{\text { Add }}$ & $\begin{array}{l}\text { Search ("Motor Activity"(Mesh) AND \#13 AND prematur* Filters: } \\
\text { Humans }\end{array}$ & $\underline{94}$ & $01: 55: 18$ \\
\hline$\# 15$ & Add & Search ("Motor Activity"(Mesh) AND \#13 AND prematur* & $\underline{107}$ & $01: 55: 09$ \\
\hline$\# 14$ & Add & Search ("Motor Activity"(Mesh) AND \#13 & $\underline{3678}$ & $01: 54: 06$ \\
\hline$\# 13$ & Add & Search ("Pregnancy"(Mesh) & $\underline{663737}$ & $01: 53: 46$ \\
\hline$\# 4$ & Add & $\begin{array}{l}\text { Search (physical activity) AND (premature OR premature) AND } \\
\text { (childbirth OR pregnancy OR parturition) }\end{array}$ & $\underline{212}$ & \\
\hline$\# 2$ & Add & Search lifting AND prematur* AND childbirth & $\underline{1}$ & $01: 44: 54$ \\
\hline$\# 1$ & Add & Search lifting AND prematur* & $\underline{41}$ & $01: 43: 29$ \\
\hline
\end{tabular}

